\title{
BMJ Open Spatio-temporal distribution and associated factors of anaemia among children aged 6-59 months in Ethiopia: a spatial and multilevel analysis based on the EDHS 2005-2016
}

\author{
Samuel Hailegebreal (D) , ${ }^{1}$ Araya Mesfin Nigatu, ${ }^{2}$ Zeleke Abebaw Mekonnen (D) , \\ Berhanu Fikadie Endehabtu (1) ${ }^{2}$
}

To cite: Hailegebreal S, Nigatu AM, Mekonnen ZA, et al. Spatio-temporal distribution and associated factors of anaemia among children aged 6-59 months in Ethiopia: a spatial and multilevel analysis based on the EDHS 2005-2016. BMJ Open 2021;11:e045544. doi:10.1136/ bmjopen-2020-045544

- Prepublication history for this paper is available online. To view these files, please visit the journal online (http://dx.doi. org/10.1136/bmjopen-2020045544).

Received 04 October 2020 Accepted 26 July 2021

D) Check for updates

(c) Author(s) (or their employer(s)) 2021. Re-use permitted under CC BY-NC. No commercial re-use. See rights and permissions. Published by BMJ.

${ }^{1}$ Department of Health Informatics, Arba Minch University, Arba Minch, Southern Nations, Ethiopia

${ }^{2}$ Department of Health Informatics, Institute of Public Health, University of Gondar, Gondar, Ethiopia

${ }^{3}$ Health System Directorate, Ethiopia Ministry of Health, Addis Ababa, Oromia, Ethiopia

Correspondence to

Samuel Hailegebreal; samuastd@gmail.com

\section{ABSTRACT}

Objectives Anaemia is a global public health problem with major health and socioeconomic consequences. Though childhood anaemia is a major public health problem in Ethiopia, there is limited evidence on the spatio-temporal variability of childhood anaemia over time in the country. Therefore, this study aimed to assess the spatio-temporal distribution and associated factors of childhood anaemia using the Ethiopian Demographic and Health Survey (EDHS) data from 2005 to 2016.

Design Survey-based cross-sectional study design was employed for the EDHS.

Setting Data were collected in all nine regions and two city administrations of Ethiopia in 2005, 2011 and 2016.

Participants The source population for this study was all children in Ethiopia aged 6-59 months. A total of 21 302 children aged $6-59$ months were included in this study.

Outcome measure The outcome variable was child anaemia status

Results The prevalence of anaemia declined from 53.9\% in 2005 to $44.6 \%$ in 2011, but it showed an increase in 2016 to $57.6 \%$. The spatial analysis revealed that the spatial distribution of anaemia varied across the regions. The spatial scan statistics analysis indicated a total of 22 clusters (relative risk $(R R)=1.5, p<0.01$ ) in 2005, 180 clusters $(R R=1.4, p<0.01)$ in 2011 and 219 clusters $(R R=1.4, p<0.0 .01)$ in 2016, significant primary clusters were identified. The child's age, mother's age, maternal anaemia status, wealth index, birth order, fever, stunting, wasting status and region were significant predictors of childhood anaemia.

Conclusions In this study, childhood anaemia remains a public health problem. The spatial distribution of childhood anaemia varied significantly across the country. Individuallevel and community-level factors were associated with childhood anaemia. Therefore, in regions with a high risk of childhood anaemia, individual-level and communitylevel factors should be intensified by allocating additional resources and providing appropriate and tailored strategies.
Strengths and limitations of this study

- This study applied different methods to analyse spatial patterns and trends, and used multilevel logistic regression models, accounting for the nested nature of Ethiopian Demographic and Health Survey (EDHS) data.

- The study was based on three consecutive EDHS datasets representing the whole country of Ethiopia.

- The cross-sectional nature of the data prevents causality from being inferred between the independent and dependent variables.

- Respondents in areas without coordinates (longitude and latitude) were excluded from the spatial analysis, which could affect the generalisability of the findings.

\section{BACKGROUND}

Anaemia is a condition characterised by a low level of haemoglobin in the blood. ${ }^{1}$ Over 273 million children aged under 5 years suffer from anaemia worldwide. ${ }^{2}$ Sub-Saharan Africa is one of the most affected regions, accounting for $53.8 \%$ of childhood anaemia. ${ }^{2}$ The WHO had developed a classification system to facilitate international comparisons of anaemia as a public health crisis. The problem is considered severe if anaemia prevalence is $\geq 40 \%$, moderate from $20 \%$ to $39.9 \%$, and mild from $5 \%$ to $19.9 \% .^{3}$ The high prevalence of anaemia and its consequences for child health, especially on their growth and development, have made it an important public health problem. Anaemia also increases the risk of mortality and morbidity that come from other diseases. ${ }^{45}$

Anaemia is a public health problem that affects populations in both industrialised and non-industrialised countries which touches all segments of the population. It is frequently 
observed among children and pregnant women who are the most vulnerable group because their iron requirements are higher than any other group. ${ }^{6}$ Anaemia is defined as a haemoglobin level below $11 \mathrm{~g} / \mathrm{dl}$ for children aged 6-59 months. Childhood anaemia is mainly caused by dietary iron deficiency; folate, vitamin $\mathrm{B}_{12}$ and vitamin A deficiencies; chronic inflammation; parasitic infections; nutritional deficiencies; haemoglobinopathies and inherited disorders. ${ }^{47}$

A report from the WHO in 2015 regarding global anaemia prevalence, using data from 2011, has shown that prevalence in Africa, southeast Asia, America and the European regions was $62.3 \%, 53.8 \%, 23.3 \%$ and $22.9 \%$, respectively. ${ }^{3}$ In sub-Saharan Africa, anaemia is a significant public health problem associated with an increased risk of death and impaired cognitive development. ${ }^{8}$

Various studies showed that the prevalence of anaemia among children aged 6-59 months was high and a severe public health problem. Evidence from various studies indicated that age of the mother, residence, maternal education status, ${ }^{9}$ an introduction of complementary foods, poor breastfeeding practice, poor utilisation of folic acid by mothers, ${ }^{10}$ maternal anaemia, ${ }^{8}$ unemployment of the parent, presence of sickle haemoglobin, household wealth index and sex of the child were associated with childhood anaemia. ${ }^{11}$ Few studies have been done on factors associated with anaemia in Ethiopia, to date; the risk areas (hot spot) of anaemia among children are not identified. Thus, this study aimed to assess the spatio-temporal patterns of anaemia among children aged under 5 years in Ethiopia over the last 15 years to evaluate whether there have been improvements in anaemia risk areas following intervention programmes in between the survey periods in Ethiopia. Geographical differences in the causes of anaemia can be partially explained by largescale variability in environmental drivers, particularly nutritional and infectious causes. ${ }^{12}$ The risk of malaria is known to be associated with elevation and land surface temperature. ${ }^{13}$ Environmental drivers of anaemia tend to show a high degree of spatial dependency. Therefore, detecting the geographical variation of anaemia during childhood is important to prioritise and design targeted intervention programmes to reduce anaemia especially in those areas with a consistently higher risk of anaemia over time. Therefore, this study attempts to fill the gap by investigating the spatio-temporal distribution of anaemia and its associated factors using multilevel model analysis in Ethiopia using the Ethiopian Demographic and Health Survey (EDHS) data between 2005 and 2016.

\section{METHODS AND MATERIALS}

\section{Study design, setting and period}

A cross-sectional survey data from three consecutive EDHS (2005, 2011 and 2016) were used for this study. The surveys were conducted at 5-year interval at the national level. Ethiopia is situated in the Horn of Africa $\left(3^{\circ}-14^{\circ} \mathrm{N}\right.$ and $\left.33^{\circ}-48^{\circ} \mathrm{E}\right)$. Administratively, the country is divided into nine regions (Afar; Amhara; BenishangulGumuz; Gambela; Harari; Oromia; Somali; Southern Nations, Nationalities, and People's Region (SNNPR); and Tigray) and two city administrations (Addis Ababa and Dire Dawa). Each region is subdivided into zones, districts, towns and kebeles (the smallest administrative units).

\section{Source and study population}

All children aged 6-59 months in Ethiopia were the source population for this study, whereas all children aged 6-59 months in the selected enumeration areas within 5 years before the survey were the study population.

\section{Sample size and sampling technique}

For the current study, a total of 21302 children aged 6-59 months were extracted from three surveys and included in the analysis. Children's record datasets were used for this analysis. The survey covered all nine regions and the two city administrations of Ethiopia. Participants were selected based on a stratified two-stage cluster sampling technique in each survey year. After excluding clusters with zero coordinates and missing information, a total of 503 clusters in 2005, 569 clusters in 2011 and 615 clusters in 2016 were used for analysis. The detailed sampling procedure was available in each survey year report. ${ }^{14-16}$

\section{Data collection tools and procedures}

The data for this analysis were extracted from Demographic and Health Survey (DHS) programme website ( www.measuredhsprogram.com) after obtaining the necessary permissions for the download and further analyses. Similarly, spatial location data (latitude and longitudinal) were extracted from the DHS website. After extraction, the missing values for the significant independent variables were excluded and the analysis was undertaken using a complete dataset. Blood specimens for anaemia testing were collected from all children aged 6-59 months for whom consent was obtained from their parents or other adults responsible for them. Blood samples were drawn from a drop of blood taken from a finger prick or a heel prick in the case of children aged 6-11 months and collected in a microcuvette. Haemoglobin analysis was carried out on-site using a battery-operated portable HemoGue analyser.

\section{Key variables and measurements}

Dependent variable

The study variables were grouped into dependent and independent variables. The dependent variable is childhood anaemia status, categorised as 'anaemic or not anaemic'. Children whose haemoglobin level was less than $11 \mathrm{~g} / \mathrm{dL}$ were considered anaemic and not anaemic otherwise.

\section{Independent variables}

Sociodemographic variables (religion, age of mother, marital status, educational status, husband education, wealth index, mother's working status, numbers of 
under-5 children), maternal and child-related variables (child's sex, child's age, birth size, birth order, maternal body mass index, maternal anaemia status, breast feeding, fever, diarrhoea, vitamin supplement, stunting status and wasting status), and community-level variables (residence, region, community women education and community women poverty).

We created community women education and community women poverty variables by aggregating the individual characteristics within their clusters. The aggregates were computed using the median values of the proportions of women in each category of a given variable. We categorised the aggregate values of a cluster into groups based on national median values, since all aggregates were not normally distributed.

Community women education was defined as the proportion of women who attended primary, secondary and higher education within the cluster. The aggregate of individual primary, secondary, and higher educational attainment can show the overall educational and academic status of women within the cluster. They were categorised into two categories: a proportion of women with higher education within the cluster and a proportion of women with lower education based on the national median value.

Community women poverty status was defined as the proportion of poor and poorest mothers within the cluster. For each cluster, the proportion of poor and poorest was aggregated and shows overall poverty status within the cluster. It was categorised into two categories based on the national median value as higher proportion of poor/poorest mothers and lower proportion of poor/ poorest mothers within a cluster.

\section{Data management and analysis}

The data were cleaned using STATA V.14.1 software and Microsoft Excel. The data were weighted using sampling weight, primary sampling unit, and strata before any statistical analysis to restore the representativeness of the survey and take into account the sampling design to obtain reliable statistical estimates.

\section{Spatial analysis}

For the spatial analysis, ArcGIS V.10.7 software and SaTScan V.9.6 software were used.

The spatial scan statistics use a circular scanning window that moves across the study area to identify a significant spatial clustering of childhood anaemia.

\section{Spatial autocorrelation analysis}

The spatial autocorrelation (Global Moran's I) statistic measures whether childhood anaemia patterns were dispersed, clustered or randomly distributed in the study area. Moran's I is a spatial statistic used to measure spatial autocorrelation by taking the entire dataset and produce a single output value that ranges from -1 to +1 . Moran's I values close to -1 indicate the spatial distribution of anaemia was dispersed, whereas Moran's I values close to +1 indicate the spatial distribution of anaemia was clustered, and an I value of 0 means anaemia is distributed randomly. Anselin's Local Moran's I identifies high-high clusters, low-low clusters and spatial outliers (high-low and low-high).

\section{Hot spot analysis (Getis-Ord Gi* statistic)}

Local Moran's I, Getis-Ord Gi* statistic, was computed to measure how spatial autocorrelation of anaemia among children aged under 5 years varies across the regions. In this analysis, Z-score and $\mathrm{p}$ value were computed to determine the statistical significance of the clustering. Statistical output with high GI* indicates 'hot spot' (high-risk areas) of childhood anaemia, whereas low GI* shows a 'cold spot' (low-risk areas) of anaemia in Ethiopia.

\section{Spatial interpolation}

The unsampled areas of Ethiopia were also predicted by using data from sampled locations through the spatial interpolation technique. There are various deterministic and geostatistical interpolation methods. Among all of the methods, ordinary Kriging and empirical Bayesian Kriging are considered the best methods since they incorporate spatial autocorrelation and statistically optimise the weight. Ordinary Kriging spatial interpolation method was used for this study for predictions of childhood anaemia in unobserved areas of Ethiopia since it had low mean square error and residual as compared with the other interpolation techniques.

\section{Spatial scan statistics analysis}

Spatial scan statistics analysis was employed to identify most likely (primary) and secondary spatial clusters of childhood anaemia. This method is widely recommended as it is very important in detecting local clusters and has higher power than other available spatial statistics methods. Bernoulli-based model was employed to test for statistically significant spatial clusters of anaemia using Kulldorff's SaTScan V.9.6 software. Children aged under 5 years with anaemia were taken as cases, and those who are not anaemic as controls to fit the Bernoulli model. The default maximum spatial cluster size of $<50 \%$ of the population was used. The scanning window with maximum likelihood was the most likely cluster, and the $p$ value was assigned to each cluster based on Monte Carlo hypothesis testing. ${ }^{17}$

\section{Associated factors of anaemia}

Four models were constructed for multilevel logistic regression analysis using 'melogit' STATA command. The first model (a random intercept model) was a null model without predictors to determine the extent of cluster variations in anaemia. The second model (model I) was adjusted with individual-level variables. The third model (model II) was adjusted for community-level variables, while the fourth model (model III) was fitted with both individual-level and community-level variables simultaneously. For model comparison, we used log-likelihood ratio (LLR) and deviance. 
Intraclass correlation (ICC), median OR (MOR) and proportional change in variance (PCV) were computed to measure the variation between clusters. The ICC quantifies the degree of heterogeneity of childhood anaemia between clusters (the proportion of the total observed individual variation in anaemia that is attributable to between-cluster variations) calculated as:

$I C C=\frac{6^{2}}{\left(6^{2}+\sigma_{b}^{2}\right)},{ }^{18}$ where, $\sigma^{2}$ is the community-level variance and $\sigma_{b}^{2}$ indicates individual-level variance. The individual variance $\left(\sigma_{b}^{2}\right)$ is equal to $\pi^{2} / 3$.

MOR is quantifying the variation of the OR between the cluster at high risk of anaemia and cluster at lower risk when randomly picking out two clusters.

MOR $=e^{\left(0.95 * \operatorname{sqrt}\left(6^{2}\right)\right) 19}$ where, $\sigma^{2}$ indicates the clusterlevel variance.

PCV is the proportion of the total observed individual variation of childhood anaemia that is attributable to between-cluster variations. In the multivariable multilevel logistic regression analysis, variables with a $p$ value of $<0.05$ were considered as statistically significant. Adjusted OR (AOR) with its corresponding 95\% CI was determined to identify factors associated with anaemia. Multicollinearity was checked using the variance inflation factor (VIF), which indicates that there is no multicollinearity because all variables have VIF less than $10 \%$. The final model was the best fitted model since it had the highest log-likelihood and the lowest deviance value.

\section{Patient and public involvement}

This study did not involve patients and the public.

\section{RESULTS}

\section{Descriptive characteristics of the study population}

A total of 21302 children with known haemoglobin levels (3868 in 2005, 8958 in 2011 and 8476 in 2016) were included in this study. The prevalence of anaemia for the three consecutive surveys was $53.9 \%, 44.6 \%$, and $57.6 \%$ in 2005, 2011, and 2016 EDHS data, respectively. The majority of the participants were in the age group of 36-47 (23.7\%), 36-47 (24.4\%), and 48-59 (22.9\%) in EDHS 2005, 2011, and 2016 surveys, respectively. The mean age of children was $32.6 \pm 15.6 \mathrm{SD}, 32.6 \pm 15.4 \mathrm{SD}$, and 31.7 $\pm 15.6 \mathrm{SD}$ in 2005, 2011, and 2016, respectively. Among the three surveys, male participants were higher in 2011 and 2016 compared with the 2005 EDHS. The majority of children were from rural settings in three surveys. The educational status of women was $78.6 \%$, $70.1 \%$, and $67.1 \%$ were unable to read and write in 2005 , 2011, and 2016 survey years, respectively. Children from poor and middle class wealth index families were more anaemic than children from rich families across the three EDHS survey years (table 1). In this study, the trends in the childhood anaemia rate fluctuate across regions (figure 1).

\section{Community-level characteristics of the study population}

This study revealed that there was a significant regional variation of childhood anaemia, with $83.3 \%, 75.5 \%$, $74.5 \%$, and $68.8 \%$ in Somali, Afar, Dire Dawa and Harari, respectively. However, Amhara and Benishangul-Gumuz regions were relatively low compared with other regions.

Also, childhood anaemia varies by place of residence. Children residing in communities with low women poverty level had a lower per cent of anaemia (51.2\%) than those in high community poverty level $(62.5 \%)$. Children from communities with low women education $(59.5 \%)$ were more anaemic than children who resided from communities with high women education (53.6\%) (table 2).

\section{Spatio-temporal distribution of anaemia among children aged 6-59 months in Ethiopia}

The spatial distribution of childhood anaemia varied across regions in all surveys. The spatial autocorrelation analysis result indicated that childhood anaemia had spatial dependency in 2005, 2011 and 2016 (Moran's I: $0.176,0.18$ and 0.09 , respectively, at $\mathrm{p}<0.01$ ).

\section{Hot spot analysis of the three surveys}

The spatial distribution of childhood anaemia in Ethiopia was different in all the three survey periods. In EDHS 2005, a high proportion of childhood anaemia was detected in Dire Dawa, Harari, Eastern Oromia, Benishangul-Gumuz in Metekel zone, Gambela, Southern and Eastern Tigray, and Somali regions, mainly Liben, Afdar, and Fafna zone which were hot spot areas within 95\% confidence level. On the other hand, Gamo Gofa, Wolayita, Hadiya, Southern Omo, and Segen zone of SNNPR, Addis Ababa, Central Oromia, Jima, and North Shewa zone were cold spot areas. In EDHS 2011, a highly significant clustering of childhood anaemia was detected in Somali, Dire Dawa, Harari, Afar, Gambela, Benishangul-Gumz, Eastern Oromia, Bale, and Arsi zone which were the hot spot areas within $95 \%$ level of confidence. Central Tigray, East and West Gojam, North Gondar, central part of Oromia, Addis Ababa and SNNPR were areas identified with the low percentage of childhood anaemia in the 2011 EDHS.

In 2016 EDHS sampled data, hot spot (high risk) regions for childhood anaemia were Somali, Dire Dawa, Harari, Gambela, and eastern and southern parts of Oromia. However, Amhara, Benishangul-Gumuz and SNNPR were identified as cold spot (low risk) regions for childhood anaemia within a 95\% CI (figure 2).

\section{Spatial interpolation}

Based on 2005 EDHS sampled data, the geostatistical analysis predicts that the highest prevalence of childhood anaemia $(65.75 \%-88.89 \%)$ was detected in East Oromia, Ilubabur, Arsi, some parts of BenishangulGumuz, Agnuak zone in Gambela, North Shewa Amhara region, South and Central Tigray, Afar in zone 2, some parts of Dire Dawa and Somali. In EDHS 2011 geostatistical analysis, a high percentage of anaemia was detected 
Table 1 Descriptive characteristics of study participants included in the analysis for childhood anaemia 5 years preceding the survey from EDHS 2005-2016 in Ethiopia

\begin{tabular}{|c|c|c|c|}
\hline Variables & $\begin{array}{l}2005(\mathrm{~N}=3868) \\
\text { frequency }(\%)\end{array}$ & $\begin{array}{l}2011(\mathrm{~N}=8958) \\
\text { frequency }(\%)\end{array}$ & $\begin{array}{l}2016(\mathrm{~N}=8476) \\
\text { frequency }(\%)\end{array}$ \\
\hline \multicolumn{4}{|l|}{ Sex of child } \\
\hline Male & $1931(49.9)$ & 4500 (51.4) & 4395 (51.9) \\
\hline Female & $1937(50.1)$ & $4358(48.7)$ & 4081 (48.2) \\
\hline \multicolumn{4}{|c|}{ Age of child in months } \\
\hline $6-11$ & $418(10.8)$ & $1029(11.5)$ & $1000(11.8)$ \\
\hline $12-23$ & $842(21.76)$ & $1804(20.14)$ & $1902(22.4)$ \\
\hline $24-35$ & $825(21.3)$ & $1895(21.2)$ & $1803(21.3)$ \\
\hline $36-47$ & $919(23.7)$ & $2184(24.4)$ & $1832(21.6)$ \\
\hline $48-59$ & $864(22.3)$ & 2047 (22.9) & 1939 (22.9) \\
\hline Mean \pm SD & $32.6 \pm 15.6$ & $32.6 \pm 15.4$ & $31.7 \pm 15.6$ \\
\hline \multicolumn{4}{|l|}{ Residence } \\
\hline Urban & $244(6.3)$ & $1047(11.7)$ & 857 (10.1) \\
\hline Rural & 3624 (93.7) & 7911 (88.3) & 7619 (89.9) \\
\hline \multicolumn{4}{|l|}{ Religion } \\
\hline Orthodox & $1624(42.0)$ & $3416(38.1)$ & 2913 (34.4) \\
\hline Muslim & $1276(33.0)$ & $3108(34.7)$ & $3432(40.5)$ \\
\hline Protestant & $836(22.0)$ & $2151(24.0)$ & $1874(22.1)$ \\
\hline Others & $133(3.0)$ & $283(3.2)$ & $258(3.0)$ \\
\hline \multicolumn{4}{|l|}{ Women age } \\
\hline $15-29$ & 1930 (49.9) & 4908 (54.9) & $4356(51.4)$ \\
\hline 30-39 & $1474(38.1)$ & $3223(36.0)$ & 3335 (39.3) \\
\hline $40-49$ & 464 (12.0) & $828(9.1)$ & $785(9.3)$ \\
\hline \multicolumn{4}{|l|}{ Women education } \\
\hline No education & $3042(78.6)$ & $6285(70.1)$ & 5685 (67.1) \\
\hline Primary & $684(17.7)$ & $2389(26.7)$ & $2275(26.8)$ \\
\hline Secondary & $136(3.5)$ & $168(1.9)$ & $346(4.1)$ \\
\hline Higher & $7(0.2)$ & 117 (1.3) & $170(2.0)$ \\
\hline \multicolumn{4}{|l|}{ Marital status } \\
\hline Single & $7(0.2)$ & $50(0.6)$ & $45(0.5)$ \\
\hline Married & 3704 (95.7) & 8425 (94.0) & 8129 (95.9) \\
\hline Widowed & $80(2.1)$ & $178(2.0)$ & $93(1.1)$ \\
\hline Divorced & $78(2.0)$ & 306 (3.4) & $210(2.5)$ \\
\hline \multicolumn{4}{|l|}{ Husband education } \\
\hline No education & 2235 (58.0) & $4532(50.9)$ & 4, $33(51.1)$ \\
\hline Primary & $1233(32.0)$ & $3710(41.7)$ & 3273 (38.6) \\
\hline Secondary & $362(9.0)$ & $412(4.6)$ & $572(6.8)$ \\
\hline Higher education & $31(1.0)$ & $255(2.8)$ & 300 (3.5) \\
\hline \multicolumn{4}{|l|}{ Wealth index } \\
\hline Poor & $1697(43.7)$ & $4048(45.2)$ & 3977 (46.9) \\
\hline Middle & $854(22.1)$ & $1873(20.9)$ & $1821(21.5)$ \\
\hline Rich & $1318(34.1)$ & 3038 (33.9) & 2678 (31.6) \\
\hline \multicolumn{4}{|c|}{ Women working status } \\
\hline Not working & 2841 (73.5) & $5793(64.7)$ & $6140(72.4)$ \\
\hline
\end{tabular}

Continued 


\begin{tabular}{llll}
\hline Table 1 Continued & & \\
\hline Variables & $\begin{array}{l}\mathbf{2 0 0 5}(\mathbf{N}=3868) \\
\text { frequency (\%) }\end{array}$ & $\begin{array}{l}\mathbf{2 0 1 1}(\mathbf{N}=8958) \\
\text { frequency (\%) }\end{array}$ & $\begin{array}{l}\mathbf{2 0 1 6}(\mathbf{N}=\mathbf{8 4 7 6}) \\
\text { frequency (\%) }\end{array}$ \\
\hline Working & $1027(26.5)$ & $3165(35.3)$ & $2336(27.6)$ \\
Total & $3868(100)$ & $8958(100)$ & $8476(100)$
\end{tabular}

EDHS, Ethiopian Demographic and Health Survey.

in Afar, most parts of Somali, Oromia in East Harerge and Borena, some parts of Dire Dawa and the Meketel zone in Benishangul-Gumuz. In 2016 EDHS, most of Somali, some parts of Gambela, Guji and some parts of Borena, East Shewa, East Harerge and Arsi in Oromia, and parts of Dire Dawa were highly prevalent areas of childhood anaemia (figure 3 ).

\section{Spatial scan statistics}

In 2005 EDHS, a total of three significant (one most likely/primary and two secondary) clusters were identified in spatial scan analysis. The primary cluster spatial window was located in Somali. It was centred at (9.018373 $\mathrm{N}, 43.110635 \mathrm{E}$ ) with a radius of $97.93 \mathrm{~km}$, a relative risk (RR) of 1.5, an LLR of 20.03, at $\mathrm{p}<0.01$. It showed that children within the spatial window were 1.5 times more likely to have a higher risk of anaemia than the children outside the spatial window areas. The secondary cluster scanning window was located in the southern part of Somali region. It was centred at $(3.998656 \mathrm{~N}, 41.240691$ E) with a radius of $92.08 \mathrm{~km}$, an $\mathrm{RR}$ of 1.7 at $\mathrm{p}<0.01$. It showed that children within the spatial window had a 1.7

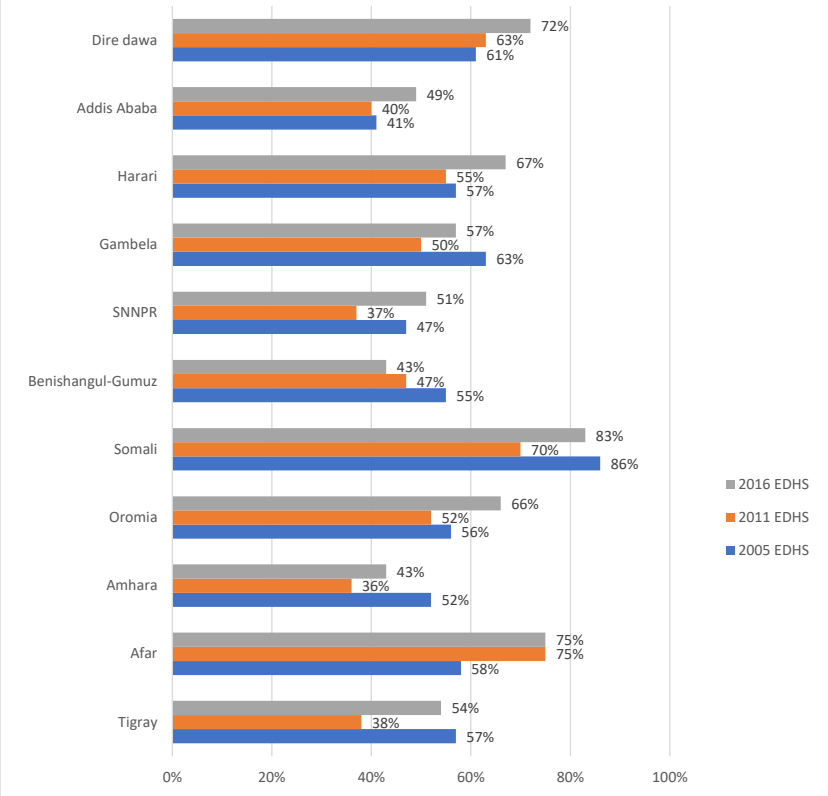

Figure 1 Trends in anaemia over time across the regions in Ethiopia, EDHS 2005-2016. EDHS, Ethiopian Demographic and Health Survey; SNNPR. Southern Nations, Nationalities, and People's Region. times higher risk of anaemia than children outside the window.

In 2011 EDHS, 10 clusters were identified and 5 of them were significant clusters at $\mathrm{p}<0.05$. A total of 180 locations/spots with a total sampled population of 2478 were found in the primary cluster spatial window with a significant $\mathrm{p}<0.01$. The primary cluster spatial window was located mainly in Somali, Afar, Eastern Oromia, Dire Dawa and Harari. It was centred at $(8.975207 \mathrm{~N}$, $43.790264 \mathrm{E}$ ) with a radius of $540.29 \mathrm{~km}$, an RR of 1.4 , an LLR of 127.79 at $\mathrm{p}<0.01$. It showed that children within the spatial window were 1.4 times more likely to be at a higher risk of anaemia than the children outside the spatial window areas. The secondary cluster spatial window was located mainly in Afar region. It was centred at $(12.758587 \mathrm{~N}, 40.175990 \mathrm{E})$ with a radius of $39.58 \mathrm{~km}$, an RR of 1.7, an LLR of 21.5 at $\mathrm{p}<0.01$.

In 2016 EDHS, seven clusters (one most likely cluster) were located in Somali, Afar, Eastern Oromia, Dire Dawa and Harari. It was centred at (7.650693 N, 47.007920 E) with a radius $912.19 \mathrm{~km}$, an RR of 1.4 and an LLR of 182.86 at $\mathrm{p}<0.01$. It showed that children within the spatial window had a 1.4 times higher risk of anaemia than those outside the window. Secondary cluster spatial window was located in Gambela. It was centred at $(8.195862 \mathrm{~N}$, $34.289837 \mathrm{E}$ ) with a radius of $29.01 \mathrm{~km}$, an LLR of 18.80 at $\mathrm{p}<0.01$ (figure 4 ).

\section{Multilevel analysis}

The ICC in the null model indicated that $19 \%$ of the total variability for childhood anaemia was due to differences between clusters. The remaining unexplained $81 \%$ were attributable to individual differences. The median OR for anaemia was 2.3 in the null model, indicating variation between clusters. If we randomly select children from two different clusters, children at the cluster with a higher risk of anaemia had 2.3 times higher odds of experiencing anaemia than children at the cluster with a lower risk of anaemia. A bivariable analysis was done to identify variables for multivariable multilevel logistic analysis. A variable with a $p$ value of $<0.25$ was considered for multivariable logistic regression analysis.

\section{Individual-level predictors for anaemia}

In multivariable multilevel mixed-effect logistic regression analysis, child's age, wealth index, mother's age, maternal anaemia status, birth order, fever, stunting and 
Table 2 Community-level factors of under-5 children who participated in EDHS (2016), Ethiopia. ( $N=8476)$

\begin{tabular}{|c|c|c|c|}
\hline Community-level factors & Not anaemic (\%) & Anaemic (\%) & Total $(100 \%)$ \\
\hline \multicolumn{4}{|l|}{ Residence } \\
\hline Urban & $435(50.6)$ & $424(49.4)$ & 857 \\
\hline Rural & $3164(41.5)$ & 4455 (58.5) & 7619 \\
\hline \multicolumn{4}{|l|}{ Region } \\
\hline Tigray & $263(46.0)$ & $309(54.0)$ & 572 \\
\hline Afar & $21(25.3)$ & $62(74.5)$ & 83 \\
\hline Amhara & $950(57.5)$ & $703(42.5)$ & 1653 \\
\hline Oromia & $1273(34.2)$ & $2446(65.8)$ & 3719 \\
\hline Somali & $58(16.7)$ & 290 (83.3) & 348 \\
\hline Benishangul-Gumuz & $51(56.6)$ & $39(43.4)$ & 90 \\
\hline SNNPR & $875(49.1)$ & $906(50.9)$ & 1781 \\
\hline Gambela & $8(42.1)$ & $11(57.9)$ & 19 \\
\hline Harari & $5(31.2)$ & $11(68.8)$ & 16 \\
\hline Addis Ababa & $82(50.9)$ & 79 (49.1) & 161 \\
\hline Dire Dawa & $9(28.1)$ & $23(71.9)$ & 32 \\
\hline \multicolumn{4}{|c|}{ Community women education } \\
\hline Low & $2281(40.5)$ & 3358 (59.5) & 5639 \\
\hline High & $1315(46.4)$ & $1520(53.6)$ & 2837 \\
\hline \multicolumn{4}{|l|}{ Community women poverty } \\
\hline Low & $1815(48.8)$ & 1905 (51.2) & 3719 \\
\hline High & $1782(37.5)$ & 2974 (62.5) & 4756 \\
\hline
\end{tabular}

EDHS, Ethiopian Demographic and Health Survey; SNNPR, Southern Nations, Nationalities, and People's Region.

wasting status were significant predictors of childhood anaemia.

Children aged between 12 and 23 months $(\mathrm{AOR}=0.66$, $95 \% \mathrm{CI}=0.53$ to 0.81 ), between 24 and 35 months $(\mathrm{AOR}=0.35,95 \% \mathrm{CI}=0.28$ to 0.43$)$, between 36 and 47 months $(\mathrm{AOR}=0.23,95 \% \mathrm{CI}=0.19$ to 0.29$)$, and between 48 and 59 months (AOR $=0.15,95 \% \mathrm{CI}=0.12$ to 0.19 ) were less likely to develop anaemia compared with children aged between 6 and 11 months.

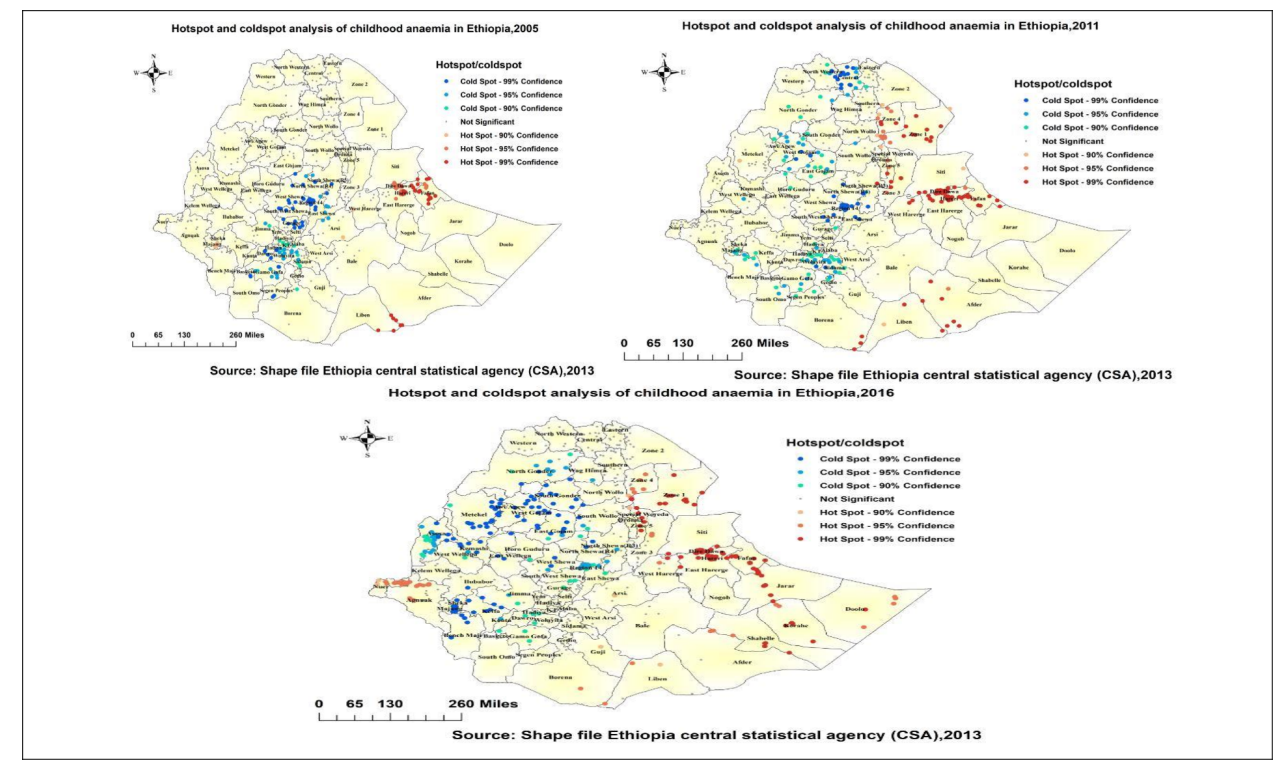

Figure 2 Hot spot and cold spot analysis of anaemia in Ethiopia, EDHS 2005-2016. EDHS, Ethiopian Demographic and Health Survey. 


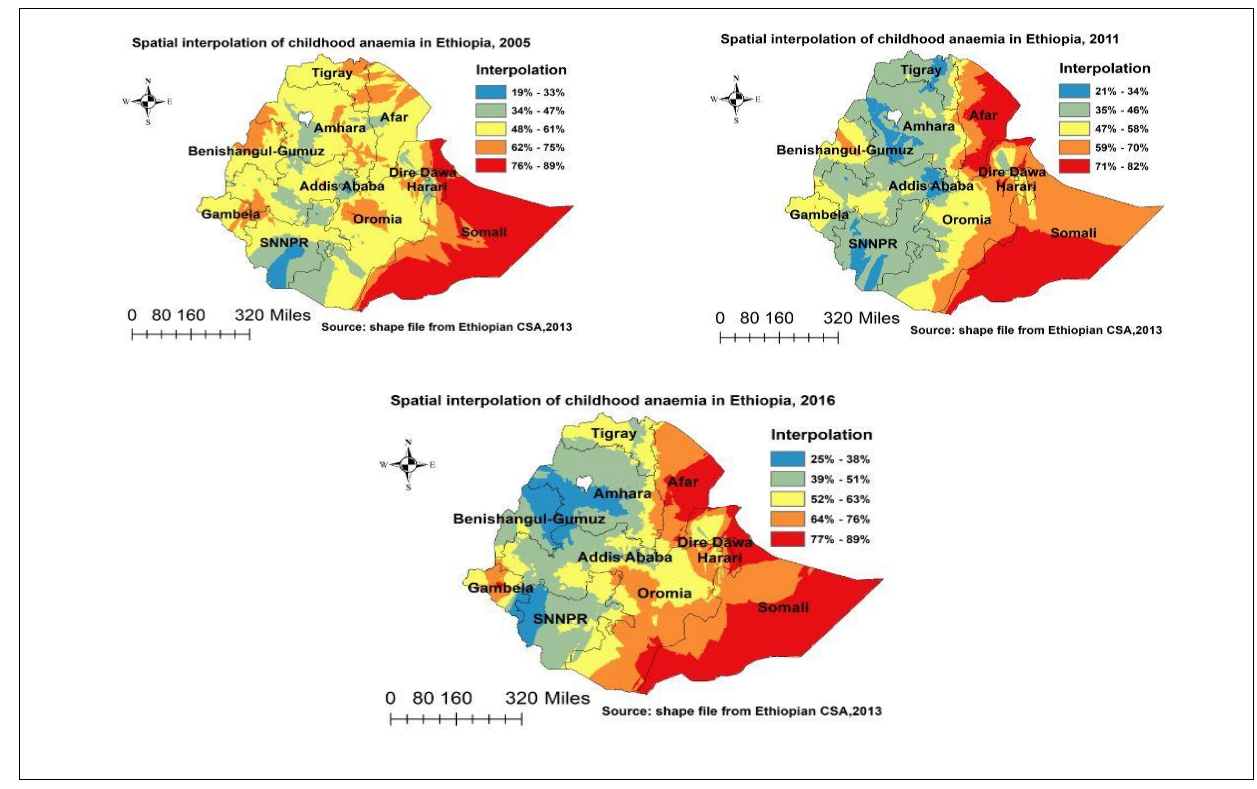

Figure 3 Ordinary Kriging interpolation of anaemia in Ethiopia, EDHS 2005-2016. CSA, Central Statistical Agency; EDHS, Ethiopian Demographic and Health Survey; SNNPR, Southern Nations, Nationalities, and People's Region.

The likelihood of developing anaemia for those children with the family wealth index of middle and rich was lower by $21 \%(\mathrm{AOR}=0.79,95 \% \mathrm{CI}=0.67$ to 0.94$)$ and $23 \%(\mathrm{AOR}=0.77,95 \% \mathrm{CI}=0.65$ to 0.91$)$, respectively, as compared with children with low wealth index. Children whose mothers' ages were between 40 and 49 years had $25 \%$ decreased odds of developing childhood anaemia compared with those aged $15-29$ years $(\mathrm{AOR}=0.75,95 \%$ $\mathrm{CI}=0.59$ to 0.95 ).

The odds of experiencing anaemia for birth orders fourth, fifth, sixth and above sixth were 1.22 times
(AOR=1.22, 95\% $\mathrm{CI}=1.01$ to 1.47 ) and 1.35 times (AOR $=1.35,95 \% \mathrm{CI}=1.08$ to 1.67$)$ higher, respectively, as compared with first order. The odds of developing anaemia of children born from a mother with a history of anaemia were 1.39 higher than those born from a mother without a history of anaemia. Children who had fever were $39 \%$ (AOR=1.39, 95\% CI: 1.24 to 1.58 ) more likely to develop anaemia than their counterparts. Children with moderate and severe stunting status were $35 \%$ (AOR $=1.35,95 \%$ CI: 1.17 to 1.54$)$ and $96 \%(\mathrm{AOR}=1.95$, 95\% CI: 1.68 to 2.28$)$ more likely to develop anaemia,

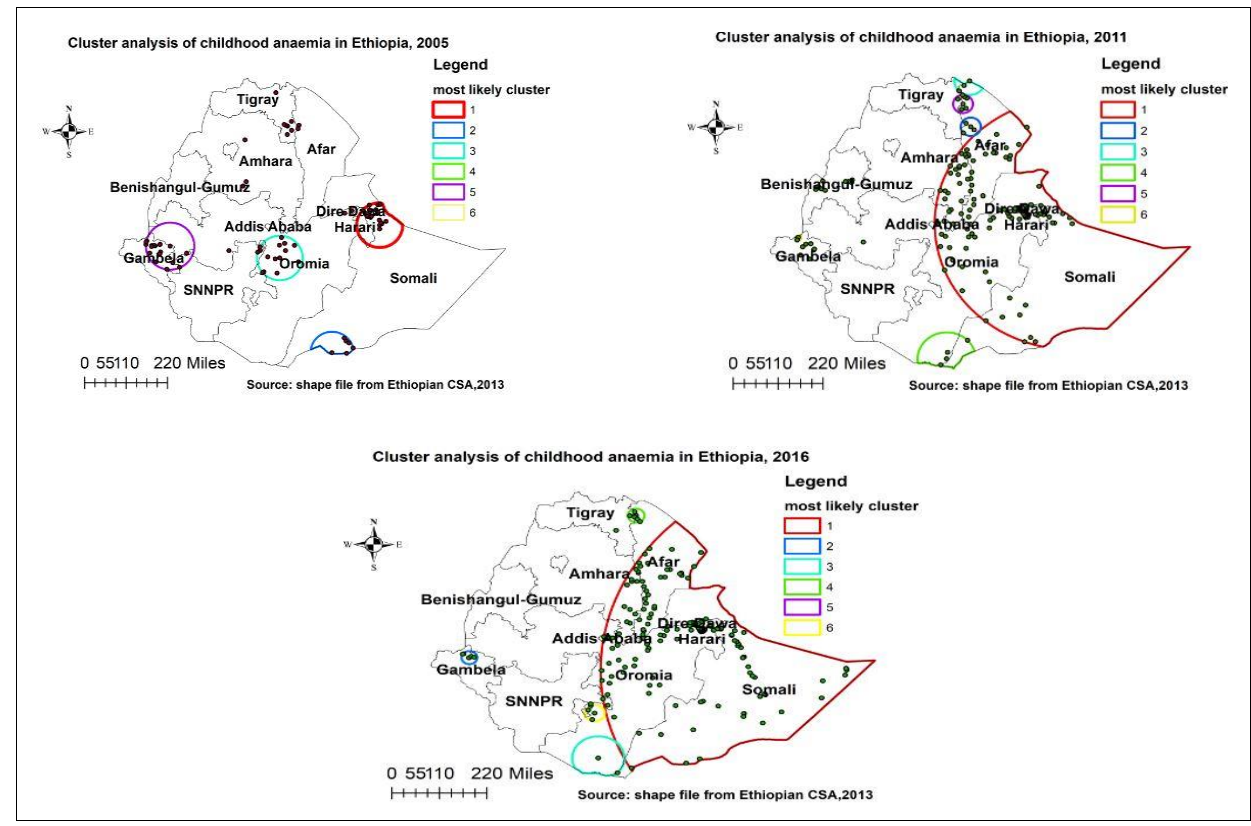

Figure 4 Spatial scan statistics analysis of anaemia in Ethiopia, EDHS, 2005-2016. CSA, Central Statistical Agency; EDHS, Ethiopian Demographic and Health Survey; SNNPR, Southern Nations, Nationalities, and People's Region. 
respectively, compared with those with no stunting status. Similarly, children who had severe wasting status were $51 \%$ more (AOR $=1.51,95 \%$ CI: 1.07 to 2.12 ) likely to develop anaemia compared with those children who had no wasting status.

\section{Community-level predictors for anaemia}

The multivariable multilevel logistic regression analysis for regions was significantly associated with communitylevel factors for childhood anaemia.

Odds of children who live in Somali were 5.65 times (AOR=5.65, 95\% CI: 3.92 to 8.16), in Dire Dawa 3.45 times (AOR=3.45, 95\% CI: 2.27 to 5.26), in Afar 3 times (AOR=3.00, 95\% CI: 2.09 to 4.34 ), and in Oromia 2.34 times (AOR=2.34, 95\% CI: 1.73 to 3.18$)$ more likely to develop childhood anaemia compared with those in Amhara region. Similarly, the odds of developing anaemia in Addis Ababa were 2 times (AOR=2.00, 95\% CI: 1.40 to 3.16), in Gambela 1.94 times ( $\mathrm{AOR}=1.94,95 \%$ CI: 1.32 to 2.84 ) and in Tigray 1.46 times (AOR $=1.46,95 \%$ CI: 1.08 to 1.98) more likely as compared with those in Amhara region. Benishangul-Gumuz and SNNPR had not significantly different prevalence of anaemia from the reference region Amhara (table 3).

\section{DISCUSSION}

This study tried to identify spatio-temporal distribution and predictors of childhood anaemia across the regions in Ethiopia. The 2005, 2011 and 2016 EDHS data were used for this analysis. The anaemia trend over these years decreased from 2005 to 2011, while the rate significantly increased from 2011 to 2016 . The study revealed that $57.56 \%$ (confidence level: $0.56 \%$ to $0.59 \%$ ) of children were anaemic in 2016. This finding is in line with a study done in Gondar, Northwest Ethiopia (58.6\%), ${ }^{20}$ higher than the study done in Cape Verde, West Africa $(51.8 \%)^{21}$ and Southern Ethiopia. ${ }^{22}$ Among children aged 6-59 months, anaemia is still considered as a significant public health problem in Ethiopia, and consequently because of various factors. Childhood anaemia in this study was influenced by background characteristics such as child's age, mother's age, region, wealth status and maternal-related factors.

The spatial analysis found that the spatial pattern of childhood anaemia across the country was substantially varied. The spatial autocorrelation analysis result indicated that childhood anaemia had spatial dependency in 2005, 2011 and 2016 (Moran's I: 0.176, 0.18, and 0.09, respectively, at $\mathrm{p}<0.01)$. These findings are in line with studies done in Nigeria, Malawi, Tanzania and Uganda. ${ }^{1123}$

Scan statistics analysis showed that Eastern Somali and the southern part of Somali region were primary (most likely) and secondary clusters in 2005, respectively. Whereas in 2011, the spatial window was located in Somali, Afar, Eastern Oromia, Dire Dawa and Harari region. It was centred at $(8.975207 \mathrm{~N}, 43.790264 \mathrm{E})$ with a radius of $540.29 \mathrm{~km}$ with a significant p value. Similarly, spatial statistics scan analysis showed that Somali, Afar, Eastern Oromia, Dire Dawa and Harari regions were hot spot areas in the 2016 EDHS. In addition, this study revealed that eastern parts of the country had similar spatio-temporal trend over the study periods.

The spatial analysis indicated the hot spot areas of anaemia were situated in the east, northeast and western parts, whereas the central, southern and northwest parts were cold spot areas of Ethiopia. The observed variability of childhood anaemia might be attributed to the regional differences in economy, healthcare facility and food availability. ${ }^{24}$

This study indicated that children aged 12-59 months were less affected by childhood anaemia. This finding was consistent with studies conducted in Ethiopia and Togo. ${ }^{925-27}$ This could be explained by the fact that children who are getting older receive a richer and complete diet, with a sufficient intake of iron which could prevent the occurrence of iron-deficiency anaemia. The finding of this study indicated that children whose mother's age was between 40 and 49 years were less anaemic as compared with those whose mother's age was 15-29 years. This finding was consistent with other studies conducted in sub-Saharan Africa and Ghana. ${ }^{828}$

Women in the age group of 15-29 years consist of adolescent population group who are more at risk of anaemia. They are vulnerable to malnutrition because they are growing faster than at any time after their first year of life which contributes to the intergenerational cycle of malnutrition. Iron deficiency is one of the most common forms of malnutrition among Ethiopian adolescent girls that result in iron-deficiency anaemia. A growing adolescent mother's and her baby's bodies may compete for nutrients, raising the infant's risk of having low birth weight; thus, the lack of nutrients might lead to anaemia.

Children from households of middle and rich wealth indices were less affected by childhood anaemia as compared with children from a poor household. This finding is in line with studies in Nigeria and Northern Ethiopia. ${ }^{1129}$ This is due to the reason that children from poor households are less likely to get iron-rich foods like animal foods and vitamin-rich foods especially vitamins $\mathrm{A}$ and $\mathrm{C}$ which are very important for iron absorption.

Maternal anaemia was highly associated with the occurrence of childhood anaemia. This finding was in line with studies done in South Africa, Haiti and India. ${ }^{30-32}$ This might be explained that mothers and children share a common home environment, socioeconomic and dietary conditions, and maternal and child anaemia may reflect the common household nutritional status, and poor maternal iron intake during pregnancy reduces breast milk, which might be the possible reason.

The findings from this study dataset indicated that the incidence of fever had an impact on childhood anaemia. This is in line with studies done in Ghana and South Ethiopia Wolayita. ${ }^{22}{ }^{33}$ This could be attributed to the infectious cause of childhood fever, mainly malaria, 
Open access

Table 3 Multilevel logistic regression analysis result of both individual and community-level factors associated with anaemia in Ethiopia, EDHS 2016

\begin{tabular}{|c|c|c|c|c|}
\hline Variables & Null model & $\begin{array}{l}\text { Model I } \\
\text { AOR }(95 \% \mathrm{Cl})\end{array}$ & $\begin{array}{l}\text { Model II } \\
\text { AOR }(95 \% \mathrm{Cl})\end{array}$ & $\begin{array}{l}\text { Model III } \\
\text { AOR }(95 \% \mathrm{Cl})\end{array}$ \\
\hline \multicolumn{5}{|c|}{ Individual-level factors } \\
\hline \multicolumn{5}{|c|}{ Age of child in months } \\
\hline $6-11$ & - & 1 & - & 1 \\
\hline $12-23$ & - & $0.66(0.54 \text { to } 0.82)^{\star *}$ & - & $0.66(0.53 \text { to } 0.81)^{\star \star}$ \\
\hline $24-35$ & - & $0.35(0.28 \text { to } 0.44)^{\star *}$ & - & $0.35(0.28 \text { to } 0.43)^{\star *}$ \\
\hline $36-47$ & - & $0.23(0.18 \text { to } 0.28)^{\star \star}$ & - & $0.23(0.19 \text { to } 0.29)^{\star *}$ \\
\hline $48-59$ & - & $0.15(0.12 \text { to } 0.19)^{\star \star}$ & - & $0.15(0.12$ to 0.19$)$ ** \\
\hline \multicolumn{5}{|l|}{ Religion } \\
\hline Orthodox & - & 1 & - & 1 \\
\hline Muslim & - & $2.07(1.77 \text { to } 2.47)^{\star \star}$ & - & 1.21 (0.97 to 1.46$)$ \\
\hline Protestant & & $1.20(1.00 \text { to } 1.48)^{\star}$ & & $1.10(0.86$ to 1.37$)$ \\
\hline Others & - & $1.55(1.07 \text { to } 2.32)^{*}$ & - & 1.44 (0.96 to 2.13$)$ \\
\hline \multicolumn{5}{|l|}{ Wealth status } \\
\hline Poor & - & 1 & - & 1 \\
\hline Middle & - & $0.71(0.61 \text { to } 0.84)^{\star *}$ & - & $0.79(0.67 \text { to } 0.94)^{\star}$ \\
\hline Rich & - & $0.72(0.63 \text { to } 0.85)^{\star *}$ & - & $0.77(0.65 \text { to } 0.91)^{\star}$ \\
\hline \multicolumn{5}{|l|}{ Child size at birth } \\
\hline Small & - & 1 & - & 1 \\
\hline Average & - & 0.96 (0.84 to 1.09$)$ & - & 0.93 (0.80 to 1.07$)$ \\
\hline Large & - & 0.94 (0.81 to 1.08 ) & - & 0.96 (0.84 to 1.10$)$ \\
\hline Birth order & & & - & \\
\hline 1st & - & 1 & - & 1 \\
\hline $2 n d-3 r d$ & - & 1.09 (0.94 to 1.28$)$ & - & 1.13 (0.97 to 1.32$)$ \\
\hline 4th-5th & - & 1.17 (0.97 to 1.40$)$ & - & $1.22(1.01 \text { to } 1.47)^{\star}$ \\
\hline 6th and above & - & 1.30 (1.05 to 1.62$)$ & - & $1.35(1.08 \text { to } 1.67)^{\star \star}$ \\
\hline \multicolumn{5}{|c|}{ No of children under 5} \\
\hline $1-2$ & - & 1 & - & 1 \\
\hline$\geq 3$ & - & $1.22(1.1 \text { to } 1.4)^{\star}$ & - & 1.09 (0.94 to 1.27$)$ \\
\hline \multicolumn{5}{|l|}{ Maternal anaemia } \\
\hline Not anaemic & - & 1 & - & 1 \\
\hline Anaemic & - & $1.51\left((1.34,1.72)^{\star \star}\right.$ & - & $1.39(1.24 \text { to } 1.58)^{\star \star}$ \\
\hline \multicolumn{5}{|l|}{ Maternal BMI } \\
\hline$\geq 18.5 \mathrm{~kg} / \mathrm{m}^{2}$ & - & 1 & - & 1 \\
\hline$<18.5 \mathrm{~kg} / \mathrm{m}^{2}$ & - & 1.12 (0.97 to 1.26$)$ & - & 1.05 (0.92 to 1.19$)$ \\
\hline \multicolumn{5}{|c|}{ Women working status } \\
\hline Not working & - & 1 & - & 1 \\
\hline Working & - & $0.88(0.77 \text { to } 0.99)^{\star}$ & - & 0.92 (0.81 to 1.04$)$ \\
\hline \multicolumn{5}{|l|}{ Women age } \\
\hline $15-29$ & - & 1 & & 1 \\
\hline $30-39$ & - & 0.91 (0.71 to 1.06$)$ & - & 0.90 (0.78 to 1.04$)$ \\
\hline $40-49$ & - & $0.75(0.59 \text { to } 1.12)^{*}$ & - & $0.75(0.59 \text { to } 0.95)^{*}$ \\
\hline \multicolumn{5}{|l|}{ Breast feeding } \\
\hline No & - & 1 & - & \\
\hline
\end{tabular}

Continued 
Table 3 Continued

\begin{tabular}{|c|c|c|c|c|}
\hline Variables & Null model & $\begin{array}{l}\text { Model I } \\
\text { AOR }(95 \% \mathrm{Cl})\end{array}$ & $\begin{array}{l}\text { Model II } \\
\text { AOR (95\% CI) }\end{array}$ & $\begin{array}{l}\text { Model III } \\
\text { AOR }(95 \% \mathrm{CI})\end{array}$ \\
\hline Yes & - & 0.92 (0.81 to 1.04$)$ & - & 0.98 (0.87 to 1.12$)$ \\
\hline \multicolumn{5}{|l|}{ Vitamins in last 6 months } \\
\hline No & - & 1 & - & \\
\hline Yes & - & 0.90 (0.81 to 1.09$)$ & - & 0.93 (0.84 to 1.05$)$ \\
\hline \multicolumn{5}{|l|}{ Diarrhoea in last 2 weeks } \\
\hline No & - & 1 & - & 1 \\
\hline Yes & - & $0.88((0.73,1.04)$ & - & 0.90 (0.76 to 1.07$)$ \\
\hline \multicolumn{5}{|l|}{ Fever in last 2 weeks } \\
\hline No & - & 1 & - & 1 \\
\hline Yes & - & $1.35(1.15 \text { to } 1.59)^{\star *}$ & - & $1.32(1.13 \text { to } 1.56)^{*}$ \\
\hline \multicolumn{5}{|l|}{ Stunting status } \\
\hline No stunting & - & 1 & - & 1 \\
\hline Moderate stunting & - & $1.27(1.10 \text { to } 1.46)^{\star \star}$ & - & $1.35(1.17 \text { to } 1.54)^{\star \star}$ \\
\hline Severely stunting & - & $1.81(1.55 \text { to } 2.11)^{\star *}$ & - & $1.96(1.68 \text { to } 2.28)^{\star *}$ \\
\hline \multicolumn{5}{|l|}{ Wasting status } \\
\hline No wasting & - & 1 & - & 1 \\
\hline Moderate wasting & - & 1.27 (1.11 to 1.45$)$ & - & 0.98 (0.80 to 1.19$)$ \\
\hline Severe wasting & - & $1.68(1.55 \text { to } 2.10)^{*}$ & - & $1.51(1.07 \text { to } 2.12)^{*}$ \\
\hline \multicolumn{5}{|c|}{ Community/cluster-level factors } \\
\hline \multicolumn{5}{|c|}{ Region } \\
\hline Amhara & - & - & 1 & 1 \\
\hline Tigray & - & - & $1.46(1.09 \text { to } 1.97)^{\star *}$ & $1.46(1.08 \text { to } 1.98)^{\star \star}$ \\
\hline Afar & - & - & $3.90(2.84 \text { to } 5.35)^{\star \star}$ & $3.00(2.09 \text { to } 4.34)^{\star \star}$ \\
\hline Oromia & - & - & $2.48(1.89 \text { to } 3.25)^{\star \star}$ & $2.34(1.73 \text { to } 3.18)^{\star *}$ \\
\hline Somali & - & - & 6.34 (4.65 to 8.63$)$ & $5.65(3.92 \text { to } 8.16)^{\star \star}$ \\
\hline Benishangul-Gumuz & - & - & 0.86 (0.62 to 1.17$)$ & 0.81 (0.58 to 1.15$)$ \\
\hline SNNPR & - & - & 1.33 (1.00 to 1.76$)$ & $1.30(0.94$ to 1.80$)$ \\
\hline Gambela & - & - & $1.93(1.38 \text { to } 2.69)^{\star \star}$ & $1.94(1.32 \text { to } 2.84)^{\star *}$ \\
\hline Harari & - & - & $3.08(2.15 \text { to } 4.43)^{\star \star}$ & $2.98(1.99 \text { to } 4.46)^{\star \star}$ \\
\hline Addis Ababa & - & - & $1.91(1.29 \text { to } 2.83)^{\star *}$ & $2.10(1.40 \text { to } 3.16)^{\star *}$ \\
\hline Dire Dawa & - & - & $3.92(2.67 \text { to } 5.77)^{\star \star}$ & $3.45(2.27 \text { to } 5.26)^{\star \star}$ \\
\hline \multicolumn{5}{|l|}{ Residence } \\
\hline Urban & - & - & 1 & 1 \\
\hline Rural & - & - & 1.40 (1.12 to 1.78$)$ & 1.28 (0.99 to 1.64$)$ \\
\hline \multicolumn{5}{|c|}{ Community women education } \\
\hline Low & - & - & 1 & 1 \\
\hline High & - & - & 1.07 (0.90 to 1.26$)$ & $1.13(0.94$ to 1.34$)$ \\
\hline \multicolumn{5}{|c|}{ Community women poverty } \\
\hline Low & - & - & 1 & 1 \\
\hline High & - & - & $1.41(1.17 \text { to } 1.68)^{*}$ & 1.15 (0.94 to 1.40$)$ \\
\hline \multicolumn{5}{|c|}{ Model comparison and random effect } \\
\hline ICC & 0.19 & 0.12 & 0.08 & 0.07 \\
\hline Log-likelihood & -4981.63 & -4513.17 & -4836.83 & -4436.60 \\
\hline Deviance & 9963.26 & 9026.34 & 9673.66 & 8873.20 \\
\hline
\end{tabular}

Continued 
Table 3 Continued

\begin{tabular}{cllll}
\hline & & Model I & Model II & Model III \\
Variables & Null model & AOR (95\% Cl) & AOR (95\% CI) & AOR (95\% CI) \\
\hline MOR & 2.30 & 1.72 & 1.42 & 1.38 \\
PCV (\%) & Reference & 41.20 & 60.10 & 62.59 \\
\hline
\end{tabular}

1: reference group; $p=0.05-0.01^{*} ; p<0.01^{* *}$.

AOR, adjusted OR; BMI, body mass index; EDHS, Ethiopian Demographic and Health Survey; ICC, intraclass correlation; MOR, median OR; PCV, proportional change in variance; SNNPR, Southern Nations, Nationalities, and People's Region.

tuberculosis, and leishmaniasis which cause anaemia by destructing red blood cells or other related mechanisms.

The nutritional and stunting status of children had a significant association with childhood anaemia. This finding is in line with previous studies conducted in South Africa, ${ }^{32}$ Bangladesh $^{34} 35$ and Ethiopia. ${ }^{36} 37$ This might be explained by the fact that children suffering from nutritional deficiency were more likely to have weak immune systems, making them vulnerable to various illnesses and unhealthiness such as parasitic infections or chronic inflammation; many of these conditions reduce the haemoglobin level in the blood leading to increased childhood anaemia. ${ }^{38}$

Furthermore, severely wasted children were more likely to be anaemic than their counterpart. This finding is consistent with previous studies. ${ }^{39} 40$ This is due to the fact that malnutrition leads to both macronutrient and micronutrient deficiencies, such as protein, iron and vitamin $\mathrm{A}$, which are responsible for iron-deficiency anaemia. Children in the birth order of fourth up to fifth and sixth and greater than sixth had higher odds of being anaemic than those in the first order. This finding was similar to studies done in India. ${ }^{8} 41$ This could be due to the distribution of scarce resources within the family and related to the maternal exhaustion of micronutrient feeding practices.

In the multilevel analysis, different individual and community factors were significantly associated with anaemia. Among the community-level variables, it was found that the odds of anaemia among children who lived in Somali, Dire Dawa, Afar and Gambela were higher than those in the Amhara region. This might be due to the fact that regional variation in the nutrient intake can cause significant health disparity, and this variability may be mediated by factors such as food availability, food customs and culture.

The potential strength of our study is the use of different methodologies for spatial pattern, trends, and a multilevel regression model because of nested or cluster samples to show the effect of individual predictors and community-level variables on the outcome variable. The study was based on a large dataset representing the whole country of Ethiopia and was weighted to make it nationally representative and adjusted for the design to get a reliable estimate. However, there were some limitations to this study. The cross-sectional nature of the data prevents causality from being inferred between the independent and dependent variables. Also, respondents' data that did not have files for coordinates (longitude and latitude) were excluded from the spatial analysis which could affect the overall result and the generalisability of the findings.

\section{CONCLUSION}

Though declining prevalence of childhood anaemia was observed from 2005 to 2011, it increased from 2011 to 2016 survey. Besides, it was spatially clustered across regions in Ethiopia. The most prominent risk areas of anaemia were detected in Afar, Somali, Dire Dawa and Oromia regions more or less consistently over the last 15 years. Child's age, mother's age, wealth index, maternal anaemia, fever, birth order, stunting, wasting and region were significant predictors among children aged 6-59 months. Therefore, public health intervention actions intended as a targeted approach to bear high-risk populations as well as geographical regions were vital to reduce childhood anaemia in Ethiopia.

Acknowledgements The authors gratefully acknowledge the support received from the University of Gondar. They also thank the Ethiopian Central Statistical Agency for providing them with the data and shape files for this study.

Contributors Proposal preparation, acquisition of data, analysis and interpretation of data were done by SH. AMN, ZAM and BFE guided the study design, data collection and analysis. SH drafted the manuscript and all authors have a substantial contribution to revising and finalising the manuscript. All authors read and approved the final manuscript.

Funding The authors have not declared a specific grant for this research from any funding agency in the public, commercial or not-for-profit sectors.

Map disclaimer The inclusion of any map (including the depiction of any boundaries therein), or of any geographic or locational reference, does not imply the expression of any opinion whatsoever on the part of BMJ concerning the legal status of any country, territory, jurisdiction or area or of its authorities. Any such expression remains solely that of the relevant source and is not endorsed by BMJ. Maps are provided without any warranty of any kind, either express or implied.

Competing interests None declared.

Patient and public involvement Patients and/or the public were not involved in the design, or conduct, or reporting, or dissemination plans of this research.

Patient consent for publication Not required.

Ethics approval Permission for data access was obtained from a major Demographic and Health Survey through an online request at (http://www. dhsprogram.com). The data used for this study were publicly available with no personal identifier. Our study was based on secondary data from Ethiopian Demographic and Health Survey and we have secured the permission letter from the main Demographic Health and Survey.

Provenance and peer review Not commissioned; externally peer reviewed. 
Data availability statement Data are available upon reasonable request. The data in which the authors used to produce this manuscript are available upon reasonable request.

Open access This is an open access article distributed in accordance with the Creative Commons Attribution Non Commercial (CC BY-NC 4.0) license, which permits others to distribute, remix, adapt, build upon this work non-commercially, and license their derivative works on different terms, provided the original work is properly cited, appropriate credit is given, any changes made indicated, and the use is non-commercial. See: http://creativecommons.org/licenses/by-nc/4.0/.

\section{ORCID iDs}

Samuel Hailegebreal http://orcid.org/0000-0003-0887-7803

Zeleke Abebaw Mekonnen http://orcid.org/0000-0003-2923-468X

Berhanu Fikadie Endehabtu http://orcid.org/0000-0001-7117-6407

\section{REFERENCES}

1 WHO. Nutritional Anaemias : Tools for Effective Prevention. World Health Organization, 2017: 1-83.

2 WHO. Global estimates of the prevalence of anaemia in infants and children aged 6 - 59 months, 2011 Global estimates of the prevalence of anaemia, all women of reproductive age, 15 - 49 years, 2011. Scaling Up Nutr [Internet], 2015. Available: http://www.who. int/nutrition/publications/micronutrients/global_prevalence_anaemia_ 2011_maps.pdf?ua=1

3 WHO. The global prevalence of anaemia in 2011. Who, 2011: 1-48. https://apps.who.int?iris/hendle/10665/177094

4 McLean E, Cogswell M, Egli I, et al. Worldwide prevalence of anaemia, who vitamin and mineral nutrition information system, 1993-2005. Public Health Nutr 2009;12:444-54.

5 Malkanthi RLDK, Silva KDRR, Jayasinghe-Mudalige UK. Risk factors associated with high prevalence of anemia among children under 5 years of age in Paddy-Farming households in Sri Lanka. Food Nutr Bull 2010;31:475-82.

6 Olivares M, Walter T, Hertrampf E, et al. Anaemia and iron deficiency disease in children. Br Med Bull 1999;55:534-43.

7 Leal LP, Batista Filho M, de Lira PIC, et al. Temporal trends and anaemia-associated factors in 6- to 59-month-old children in northeast Brazil. Public Health Nutr 2012;15:1645-52.

8 Moschovis PP, Wiens MO, Arlington L, et al. Individual, maternal and household risk factors for anaemia among young children in subSaharan Africa: a cross-sectional study. BMJ Open 2018;8:e019654.

9 Nambiema A, Robert A, Yaya I. Prevalence and risk factors of anemia in children aged from 6 to 59 months in Togo: analysis from Togo demographic and health survey data, 2013-2014. BMC Public Health 2019;19:215.

10 Malako BG, Teshome MS, Belachew T. Anemia and associated factors among children aged 6-23 months in Damot Sore District, Wolaita Zone, South Ethiopia. BMC Hematol 2018;18:14.

11 Gayawan E, Arogundade ED, Adebayo SB. Possible determinants and spatial patterns of anaemia among young children in Nigeria: a Bayesian semi-parametric modelling. Int Health 2014;6:35-45.

12 Desalegn Wolide A, Mossie A, Gedefaw L. Nutritional iron deficiency anemia: magnitude and its predictors among school age children, Southwest Ethiopia: a community based cross-sectional study. PLoS One 2014;9:e114059.

13 Guerra CA, Snow RW, Hay SI. Defining the global spatial limits of malaria transmission in 2005. Adv Parasitol 2006;62:157-79.

14 Agency CS, Macro ORC. Ethiopia demographic and health survey 2005. Heal San Fr 2006 http://www.measuredhs.com/pubs/pdf/ FR179/FR179[23June2011].pdf

15 Central Statistical Agency [Ethiopia], ICF International. Ethiopia demographic and health survey 2011, 2012: 1-452.

16 ECSA. Ethiopian demographic health survey 2016, 2016: 161.

17 Kulldorff M. SatScan user guide 2006, 2018.

18 Bartko JJ. The intraclass correlation coefficient as a measure of reliability. Psychol Rep 1966;19:3-11.

19 Assessment IS. Understanding Variability in Multilevel Models Sophia Rabe-Hesketh Example : PISA (Programme for International Student Assessment) PISA : Distribution of SES.
20 Enawgaw B, Workineh Y, Tadesse S, et al. Prevalence of anemia and associated factors among hospitalized children attending the University of Gondar Hospital, Northwest Ethiopia. EJIFCC 2019;30:35-47.

21 Semedo RML, Santos MMAS, Baião MR, et al. Prevalence of anaemia and associated factors among children below five years of age in Cape Verde, West Africa. J Health Popul Nutr 2014;32:646-57.

22 Tiku YS, Mekonnen TC, Workie SB, et al. Does anaemia have major public health importance in children aged 6-59 months in the Duggina Fanigo district of Wolaita zone, southern Ethiopia? Ann Nutr Metab 2018;72:3-11.

23 Roberts DJ, Matthews G, Snow RW, et al. Investigating the spatial variation and risk factors of childhood anaemia in four sub-Saharan African countries. BMC Public Health 2020;20:126.

24 Diao X, Taffesse AS, Thurlow J. NEWSLETTER - Ethiopia Strategy Support Program II (ESSP-II) Highlights of Presentations Summer Fall 2010 : h NEWSLETTER - Ethiopia Strategy Support Program II (ESSP-II) Capacity Building Initiatives 2010, 2010.

25 Gebreweld A, Ali N, Ali R, et al. Prevalence of anemia and its associated factors among children under five years of age attending at Guguftu health center, South Wollo, northeast Ethiopia. PLoS One 2019;14:e0218961.

26 Mohammed SH, Habtewold TD, Esmaillzadeh A. Household, maternal, and child related determinants of hemoglobin levels of Ethiopian children: hierarchical regression analysis. BMC Pediatr 2019;19:1-10.

27 Keikhaei B, Zandian K, Ghasemi A, et al. Iron-Deficiency anemia among children in Southwest Iran. Food Nutr Bull 2007;28:406-11.

28 Campbell JR, Holland J. Development research. Focaal 2007;2005:3-17.

29 Gebreegziabiher G, Etana B, Niggusie D. Determinants of anemia among children aged 6-59 months living in Kilte Awulaelo Woreda, Northern Ethiopia. Anemia 2014;2014:1-9.

30 Ayoya MA, Ngnie-Teta I, Séraphin MN, et al. Prevalence and risk factors of anemia among children 6-59 months old in Haiti. Anemia 2013;2013:1-3.

31 Pasricha S-R, Black J, Muthayya S, et al. Determinants of anemia among young children in rural India. Pediatrics 2010;126:e140-9.

32 Ntenda PAM, Nkoka O, Bass P, et al. Maternal anemia is a potential risk factor for anemia in children aged 6-59 months in Southern Africa: a multilevel analysis. BMC Public Health 2018;18:650.

33 Shenton LM, Jones AD, Wilson ML. Factors Associated with Anemia Status Among Children Aged 6-59 months in Ghana, 2003-2014. Matern Child Health J 2020;24:483-502.

34 Khan JR, Awan N, Misu F. Determinants of anemia among 6-59 months aged children in Bangladesh: evidence from nationally representative data. BMC Pediatr 2016;16:3.

35 Rahman MS, Mushfiquee M, Masud MS, et al. Association between malnutrition and anemia in under-five children and women of reproductive age: evidence from Bangladesh demographic and health survey 2011. PLoS One 2019;14:e0219170.

36 Belachew A, Tewabe T. Under-five anemia and its associated factors with dietary diversity, food security, stunted, and deworming in Ethiopia: systematic review and meta-analysis. Syst Rev 2020;9:31.

37 Malako BG, Asamoah BO, Tadesse M, et al. Stunting and anemia among children 6-23 months old in Damot sore district, southern Ethiopia. BMC Nutr 2019;5:3.

38 Pelletier DL, Frongillo EA, Schroeder DG, et al. The effects of malnutrition on child mortality in developing countries. Bull World Health Organ 1995;73:443-8.

39 Takele WW, Baraki AG, Wolde HF, et al. Anemia and contributing factors in severely malnourished infants and children aged between 0 and 59 months admitted to the treatment centers of the Amhara region, Ethiopia: a multicenter chart review study. Anemia 2021;2021:1-8.

40 Caulfield LE, Richard SA, Rivera JA. Chapter 28. Stunting,Wasting, and Micronutrient Deficiency Disorders. In: Dis control priorities DEV Ctries. 2nd Ed, 2006: 551-68.

41 Goswmai S, Das KK. Socio-Economic and demographic determinants of childhood anemia. J Pediatr 2015;91:471-7. 